\title{
CORRECTION
}

\section{Correction to: A Nautilus kidney}

\author{
Bo-Sheng $\mathrm{Wu}^{1} \cdot$ Yang $\mathrm{Ho}^{2} \cdot$ Chih-Yu Yang ${ }^{1,2,3,4,5}$
}

Published online: 11 August 2020

(c) Japanese Society of Nephrology 2020

\section{Correction to: Clinical and Experimental Nephrology https://doi.org/10.1007/s10157-020-01915-7}

In the original publication of the article, the second sentence under the heading, Case presentation appears incorrectly as A computed tomographic (CT) scan demonstrated left-sided hydronephrosis (Fig. 1). The corrected text should read as "A computed tomographic (CT) scan demonstrated right-sided hydronephrosis (Fig. 1)".

Publisher's Note Springer Nature remains neutral with regard to jurisdictional claims in published maps and institutional affiliations.

The original article can be found online at https://doi.org/10.1007/ s10157-020-01915-7.

\section{Chih-Yu Yang}

cyyang3@vghtpe.gov.tw

1 Faculty of Medicine, School of Medicine, National YangMing University, Taipei, Taiwan

2 Division of Nephrology, Department of Medicine, Taipei Veterans General Hospital, No. 201, Section 2, Shih-Pai Road, Taipei 11217, Taiwan

3 Institute of Clinical Medicine, School of Medicine, National Yang-Ming University, Taipei, Taiwan

4 Stem Cell Research Center, National Yang-Ming University, Taipei, Taiwan

5 Center for Intelligent Drug Systems and Smart Bio-devices (IDS2B), Hsinchu, Taiwan 